\title{
Fair Valuation and Risk Assessment of Dynamic Hybrid Products in Life Insurance: A Portfolio Consideration*
}

\author{
Alexander Bohnert and Nadine Gatzert \\ Department of Insurance Economics and Risk Management, Friedrich-Alexander-University (FAU) of \\ Erlangen-Nürnberg, Lange Gasse 20, Nuremberg 90403, Germany. \\ E-mails: alexander.bohnert@fau.de; nadine.gatzert@fau.de
}

Dynamic hybrid products are innovative life insurance products particularly offered in the German market and intended to meet new consumer needs regarding stability and upside potential. These products are characterised by a periodical rebalancing process between the policy reserves (i.e. the premium reserve stock), a guarantee fund and an equity fund. The policy reserve thereby corresponds to the one also valid for traditional participating life insurance products. Hence, funds of dynamic hybrids that are allocated to the policy reserves in times of adverse capital market environments earn the same policy interest rate determined for the participating life insurance policyholders and, hence, at least a guaranteed interest rate. In this paper, we study the fair valuation and risk situation of an insurer offering both dynamic hybrid and traditional participating life insurance contracts. The results reveal considerable interaction effects between the two contract types within the portfolio that strongly depend on the portfolio composition, thereby emphasising merits as well as risks associated with offering dynamic hybrids.

The Geneva Papers (2014) 39, 148-172. doi:10.1057/gpp.2013.10

Keywords: life insurance; risk measurement; risk-neutral valuation; dynamic hybrid; constant proportion portfolio insurance

\section{Introduction}

Dynamic hybrid products are innovative life insurance and deferred annuity products particularly offered on the German market. The aim of these products is to meet new consumer needs by combining the stability of traditional life insurance (by means of the conventional policy reserves) with the upside potential of unit-linked policies (through investing in a guarantee and/or equity fund). While the version of this class of contracts first introduced (referred to as "static hybrid") used a decomposition of the premiums to ensure the guarantee promised to policyholders, dynamic hybrid products use a periodical dynamic rebalancing of the account value into two to three different investments based on a constant proportion portfolio insurance-type strategy (CPPI). ${ }^{1}$

\footnotetext{
* This paper has been granted the 2013 Shin Research Excellence Award - a partnership between The Geneva Association and the International Insurance Society - for its academic quality and relevance by decision of a panel of judges comprising both business and academic insurance specialists.

${ }^{1}$ See Leland (1980), Rubinstein and Leland (1981), and Black and Jones (1987) regarding CPPI mechanisms.
} 
The three typical investments of " 3 -fund dynamic hybrid products" include the policy reserves, a guarantee fund (that loses at most a certain percentage in each period) and a risky equity fund. In particular, in times of adverse capital market environments, for instance, funds may be shifted short term from the guarantee fund and the equity fund to the conventional policy reserves (and hence the premium reserve stock), thus earning the same policy interest rate credited to the traditional life insurance contracts, which is at least the guaranteed actuarial interest rate. Hence, considerable interaction effects can be expected between the traditional participating life insurance policies and the dynamic hybrid products when considering a mixed portfolio, which may have a strong impact on an insurer's risk situation and also on the fair valuation of both contract types. The aim of this paper is to comprehensively study these interaction effects with focus on fair valuation and risk measurement for an insurer with a product portfolio consisting of traditional life insurance contracts and dynamic hybrid products for a specific rebalancing mechanism in depth.

In the early versions of hybrid products, premiums were split in order to meet a certain (e.g. money-back) guarantee, such that one premium part is invested in the policy reserves and the remaining part is invested in a risky equity fund, whereby the policy reserves are assumed to earn at least the minimum actuarial interest rate. ${ }^{2}$ The drawback of this approach is the fact that only a minor portion of the premiums is available for the investment in risky funds with upside potential, as the equity fund's value is assumed to drop to zero in the worst case in one period, for example, one month or even one day, which can be considered rather unrealistic. Hence, newer versions of the products used a guarantee fund, which is equal to the equity fund but ensures that the guarantee fund value does not lose more than a certain percentage within one period. Thus, the premium part invested in the policy reserves can be relatively lower, such that policy reserves are partly relieved from having to cover the full guarantee promised to the hybrid contracts. However, to meet a final guarantee after more than one period, funds have to be shifted from the guarantee fund to the policy reserves in case the guarantee fund has dropped, which is the starting point for dynamically reallocating the investment as done in the case of dynamic hybrid products.

Until recently, the literature has paid only little attention to dynamic hybrid products, which are mainly discussed in the non-academic literature and there without providing a model framework or numerical studies. Bettels et al., ${ }^{3}$ for instance, indicate that there is a need to analyse interactions of dynamic hybrid products with the existing portfolio of policies to adequately assess the risk for insurers that are connected to dynamic hybrid products. In addition to the risk for insurers, they point out that, since the guarantees in the guarantee fund are provided by external investment companies, reputational risk may arise in case these investment companies fail to keep their guarantees. Other qualitative discussions by actuaries are provided in Menzel $^{4}$ and Siebert. ${ }^{5}$ Menzel $^{4}$ highlights the potential risk

\footnotetext{
${ }^{2}$ See, for example, Kochanski and Karnarski (2011) for a more detailed and formal description of these products.

${ }^{3}$ Bettels et al. (2011).

${ }^{4}$ Menzel (2008).

${ }^{5}$ Siebert (2008).
} 
an insurer would face with dynamic hybrid products in the portfolio, as the portfolio of traditional polices sells an option to the policyholders of dynamic hybrid products, whose value may not be negligible. Siebert ${ }^{5}$ opposes that there are not only risks connected to dynamic hybrid products but also benefits for an insurance company selling dynamic hybrid products in addition to traditional policies, as there are positive substitution effects for both products. Thus, while both articles address potential interaction effects of a portfolio of dynamic hybrid products with a traditional insurance portfolio, they do not provide a model or numerical examples. A model framework for hybrid contracts is presented in Kochanski and Karnarski, ${ }^{6}$ who calculate solvency capital requirements according to Solvency II for static as well as dynamic hybrid products. They implement a partial internal model for a portfolio of 3-fund dynamic hybrid products including a rules-based shifting process to reallocate the contracts' account value each month. Since focus is laid on determining solvency capital requirements in accordance to Solvency II, they do not analyse interaction effects within a portfolio of dynamic hybrid products and traditional contracts.

In this paper, we contribute to the literature by analysing the impact of dynamic hybrid products on the fair valuation and risk assessment of an insurer with a portfolio consisting of traditional participating life insurance contracts and dynamic hybrid products. We thereby provide a model framework for the development of a pool of participating life insurance contracts and the accumulation phase of a pool of dynamic hybrid products that allows us to study interaction effects between the two types of products in depth. The dynamic reallocation of funds of the dynamic hybrid products over time is mainly based on Kochanski and Karnarski, ${ }^{6}$ whereas the surplus distribution mechanism for the policy reserves of the traditional contracts is based on the smoothing scheme in Grosen and Jørgensen. ${ }^{7}$ Our findings show strong interdependencies between traditional participating life insurance contracts and innovative dynamic hybrid products, which can considerably affect the fair value of the two products as well as the insurer's risk situation. Policyholders of the two products can either profit or lose from the portfolio composition and the arising substitution effects, depending on the contract parameters and especially the guarantee level offered to the dynamic hybrid policyholders, which strongly impacts the dynamic reallocation of funds. In addition, the findings show that even though the situation is fair from the equityholders' perspective, this is not necessarily the case for the two life insurance products, whose present values vary considerably depending on the portfolio composition and the choice of input parameters.

The remainder of the paper is structured as follows. The next section presents the model framework of the insurance company offering participating life insurance policies and the dynamic hybrid products including fair valuation and risk measurement. The subsequent section contains a numerical analysis and the final section concludes.

\footnotetext{
${ }^{6}$ Kochanski and Karnarski (2011).

${ }^{7}$ Grosen and Jørgensen (2000).
} 
Table 1 Balance sheet of the life insurer at time $t$

$\left.\begin{array}{ll}\hline \text { Assets } & \multicolumn{2}{c}{\text { Liabilities }} \\ \hline A_{t}^{\text {longterm }} & \begin{array}{l}P R_{t}^{\text {PLI }} \\ A_{t}^{\text {shortterm }}\end{array} \\ G F_{t}^{A} & \left.\begin{array}{l}\text { DH } \\ \text { DHP }\end{array}\right\} P R_{t} \\ E F_{t}^{A} & G F_{t}^{L} \\ & E F_{t}^{L}\end{array}\right\}$

\section{Model framework}

\section{Modelling the insurance company}

We consider a life insurance company with a product portfolio consisting of traditional participating life insurance $(P L I)$ and dynamic hybrid products $(D H P)$. Traditional participating life insurance (traditional guaranteed with-profits policies) place the contracts' available funds entirely and throughout the whole contract term in the actuarial policy reserves $(P R)$. In the case of dynamic hybrid products, the policyholder's funds are dynamically allocated between up to three pots, the policy reserves, a guarantee fund $(G F)$ and an equity fund $(E F)$, in order to ensure the guarantee promised to the policyholder.

Table 1 shows the balance sheet of the life insurance company at time $t$. The liabilities side comprises accounts for the policy reserves $\left(P R_{t}\right)$, (synthetically) partitioned in policy reserves for the participating life insurance contracts $\left(P R_{t}^{P L I}\right)$ and for the dynamic hybrid products $\left(P R_{t}^{D H P}\right)$, accounts for the dynamic hybrid products' guarantee fund $G F_{t}^{L}$ and equity fund $E F_{t}^{L}$, plus an account $B_{t}$ that serves as buffer. Thus, $B_{t}$ is residually given by the company's total assets $\left(A_{t}\right)$ minus the policyholders' accounts, that is, $P R_{t}, G F_{t}^{L}$ and $E F_{t}^{L}$. For simplification, $B_{t}$ is not further subdivided into a buffer account and equity. The policy reserves for participating life insurance products as well as dynamic hybrid products, that is $P R_{t}^{P L I}$ and $P R_{t}^{D H P}$, are treated as one account, as their separation into two accounts is conducted to keep track of the corresponding investment on the asset side (the premium reserve stock).

The asset side of the balance sheet is structured as follows. The company's total assets are allocated to two different groups of investments, the fund investments for the dynamic hybrid product policyholders (the guarantee fund $G F_{t}^{A}$ and the equity fund $E F_{t}^{A}$ ), which are the offsetting items to $G F_{t}^{L}$ and $E F_{t}^{L}$ on the liabilities side, ${ }^{8}$ and the remaining assets, hereafter referred to as "company's assets".

Even though policy reserves of the participating life insurance and dynamic hybrid products on the liabilities side are treated equally, the corresponding assets cannot be handled alike, since maturities differ considerably. Unlike the policy reserves of participating life insurance contracts that have to and can be invested for a relatively

\footnotetext{
${ }^{8}$ For the insurer, these accounts are not risk-bearing, as market risks are fully carried by the policyholder. However, the default of a guarantee fund would represent a reputational risk for the insurance company.
} 
long period of time, funds in the policy reserves of the dynamic hybrid product might only be available in this account for a short period, until they are shifted to the guarantee fund or the equity fund. Therefore, we assume that the company's assets are split into long-term investments $A_{t}^{\text {longterm }}$ and short-term investments $A_{t}^{\text {shortterm }}$, whereby the buffer account is also assumed to be invested short term due to its smoothing characteristics over time.

To be able to distinguish between the beginning and the end of a period, we use " + " and "-" to denote the period's beginning and end, respectively. Hence, at $t=0^{+}$, that is at the beginning of the first period, $B_{0^{+}}$is filled up by an initial contribution of the company's owners. Analogously to the policyholders, we do not assume further payments from the equityholders during the lifetime of the company. Furthermore, equityholders are not able to withdraw funds from the company until liquidation at time $T$, at which they receive an interest-bearing payback of their initial contribution, in case the company's funds are sufficient to cover the policyholders' liabilities. At the end of the considered time horizon, that is at time $T^{-}$, policyholders holding a traditional participating life insurance contract receive their final sum insured including their surplus participation, while policyholders with a dynamic hybrid product are paid out the sum of their three pots, that is, their final account value at the end of year $T\left(A V_{T^{-}}^{D H P}=P R_{T^{-}}^{D H P}+G F_{T^{-}}^{L}+E F_{T^{-}}^{L}\right)$. In addition, policyholders of both contracts receive a terminal bonus. In the present analysis, focus is only laid on the accumulation phase, while the payout is assumed to be a single lump sum payment instead of a lifelong annuity.

Furthermore, policyholders pay their single premiums $P^{P L I}$ and $P^{D H P}$ resulting to initial policy reserves of the participating life insurance contracts of

$$
P R_{0^{+}}^{P L I}=P^{P L I},
$$

and an initial account value of the dynamic hybrid products of

$$
A V_{0^{+}}^{D H P}=P^{D H P} .
$$

The distribution of funds in $A V_{0^{+}}^{D H P}$ to $P R_{0^{+}}^{D H P}, G F_{0^{+}}^{L}$ and $E F_{0^{+}}^{L}$ is laid out in the subsequent section. To focus on interactions of the two product types within a life insurer, the contract term $T$ is assumed to coincide with the lifetime of the considered insurance company.

\section{Development of assets}

At the beginning of period $t$, the company's asset investments are thus given by

$$
\begin{gathered}
A_{t^{+}}^{\text {longterm }}=P R_{t^{+}}^{P L I}, \\
A_{t^{+}}^{\text {shortterm }}=P R_{t^{+}}^{D H P}+B_{t^{+}}, \\
G F_{t^{+}}^{A}=G F_{t^{+}}^{L}, \\
E F_{t^{+}}^{A}=E F_{t^{+}}^{L} .
\end{gathered}
$$


We assume that the guarantee fund evolves analogously to the equity fund except for the downside protection. ${ }^{6}$ Hence, there are three types of investments, including long-term investments corresponding to the policy reserves of the traditional participating life insurance contracts, short-term investments that correspond to the part of policy reserves that arise from the dynamic hybrid products and the buffer, and the equity fund. These three investments are all assumed to evolve according to a geometric Brownian motion given by the following stochastic differential equation,

$$
\mathrm{d} I_{t}^{i}=\mu_{i} \cdot I_{t}^{i} \cdot \mathrm{d} t+\sigma_{i} \cdot I_{t}^{i} \cdot d W_{t, i}^{P}, i=1,2,3,
$$

with constant drift $\mu_{i}$ and volatility $\sigma_{i}, P$-Brownian motions $\mathrm{d} W_{t, i}^{P}$ defined on the probability space $(\Omega, \mathcal{F}, P)$ with the linear correlations $\mathrm{d} W_{t, i}^{P} \cdot \mathrm{d} W_{t, j}^{P}=\rho_{i, j}$. The solution of the equation results in ${ }^{9}$

$$
I_{t}^{i}=I_{0}^{i} \cdot \exp \left(\left(\mu_{i}-\frac{1}{2} \cdot \sigma_{i}^{2}\right) \cdot t+\sigma_{i} \cdot \mathrm{d} W_{t, i}^{P}\right) .
$$

At the end of period $t$, the asset items are thus given by

$$
\begin{gathered}
A_{(t+\Delta t)^{-}}^{\text {longterm }}=A_{t^{+}}^{\text {longterm }} \cdot \frac{I_{t+\Delta t}^{1}}{I_{t}^{1}}, \\
A_{(t+\Delta t)^{-}}^{\text {shortterm }}=A_{t^{+}}^{\text {shortterm }} \cdot \frac{I_{t+\Delta t}^{2}}{I_{t}^{2}}, \\
E F_{(t+\Delta t)^{-}}^{A}=E F_{t^{+}}^{A} \cdot \frac{I_{t+\Delta t}^{3}}{I_{t}^{3}} \\
G F_{(t+\Delta t)^{-}}^{A}=G F_{t^{+}}^{A} \cdot \max \left(1-\lambda ; y \cdot \frac{I_{t+\Delta t}^{3}}{I_{t}^{3}}\right),
\end{gathered}
$$

where the development of the guarantee fund is determined by a fraction $y$ of the performance of the equity fund, since the downside protection has to be financed. In particular, we can show that in the present setting, the fraction $y$ is constant over time for a given set of parameters $\lambda, r_{f}, \sigma_{3}$ and $\Delta t$ and thus independent of the current value of the guarantee fund, as we assume that a put option on the equity fund with price $P_{t}$ and a strike price $(1-\lambda) \cdot G F_{t^{+}}^{A}$ with $0 \leqslant \lambda \leqslant 1$ is used for the downside protection (alternatively, a guarantee fund can also be secured by a CPPI-based strategy). In particular, only a fraction of the guarantee fund $y \cdot G F_{t^{+}}^{A}$ with $0 \leqslant y \leqslant 1$ can be invested in the equity fund, as the put option price $P_{t}=(1-y) \cdot G F_{t^{+}}^{A}$ has to be paid for hedging the downside risk. The put option price $P_{t}$ can be calculated via the Black-Scholes formula, which is given by

$$
P_{t}=(1-\lambda) \cdot G F_{t^{+}}^{A} \cdot \exp \left(-r_{f} \cdot \Delta t\right) \cdot \Phi\left(d_{1}\right)-y \cdot G F_{t^{+}}^{A} \cdot \Phi\left(d_{1}-\sigma_{3} \sqrt{\Delta t}\right)
$$

\footnotetext{
${ }^{9}$ See Björk (2009).
} 


$$
\begin{aligned}
d_{1} & =\frac{\ln \left(\frac{(1-\lambda) \cdot G F_{t^{+}}^{A}}{y \cdot G F_{t^{+}}^{A}}\right)-\left(r_{f}-\frac{1}{2} \cdot \sigma_{3}^{2}\right) \cdot \Delta t}{\sigma_{3} \cdot \sqrt{\Delta t}} \\
& =\frac{\ln \left(\frac{1-\lambda}{y}\right)-\left(r_{f}-\frac{1}{2} \cdot \sigma_{3}^{2}\right) \cdot \Delta t}{\sigma_{3} \cdot \sqrt{\Delta t}} .
\end{aligned}
$$

Hence, the available funds in the guarantee fund at time $t^{+}$can be split into an investment in the equity fund and the payment for the put option, resulting in

$$
\begin{aligned}
G F_{t^{+}}^{A}= & y \cdot G F_{t^{+}}^{A}+P_{t}=y \cdot G F_{t^{+}}^{A}+(1-\lambda) \cdot G F_{t^{+}}^{A} \\
& \cdot \exp \left(-r_{f} \cdot \Delta t\right) \cdot \Phi\left(d_{1}\right)-y \cdot G F_{t^{+}}^{A} \\
& \cdot \Phi\left(d_{1}-\sigma_{3} \sqrt{\Delta t}\right),
\end{aligned}
$$

which can be rewritten as

$$
1=y+(1-\lambda) \cdot \exp \left(-r_{f} \cdot \Delta t\right) \cdot \Phi\left(d_{1}\right)-y \cdot \Phi\left(d_{1}-\sigma_{3} \sqrt{\Delta t}\right)
$$

The latter equation is thus independent of $G F_{t^{+}}^{A}$ for a given set of parameters and must only be solved once for $y$ using a root-finding algorithm (as $d_{1}$ depends on $y$ as well), which considerably simplifies the further simulation analysis.

The total assets amount of the balance sheet thus results to

$$
A_{(t+\Delta t)^{-}}=A_{(t+\Delta t)^{-}}^{\text {longterm }}+A_{(t+\Delta t)^{-}}^{\text {shortterm }}+E F_{(t+\Delta t)^{-}}^{A}+G F_{(t+\Delta t)^{-}}^{A} .
$$

\section{Development of liabilities}

On the liability side, all policy reserves are annually compounded with a policy interest rate $r_{t}^{P}$ that in the following is assumed to be based on Grosen and $\mathbf{J} \varnothing$ rgensen $^{7}$ (but can as well be replaced by other smoothing mechanisms depending on the regulatory rules of the respective country) ${ }^{10}$

$$
r_{t}^{P}=\max \left(r^{G}, \alpha \cdot\left(\frac{B_{t^{+}}}{P R_{t^{+}}^{P L I}+P R_{t^{+}}^{D H P}}-\gamma\right)\right),
$$

\footnotetext{
${ }^{10}$ Note that the amount of surplus participation typically depends on how prudent the insurer calculates premiums - when taking into account mortality risk and costs, surplus is increased by means of the mortality and the cost result, which comes in addition to the investment result (see, e.g. Bohnert and Gatzert (2012) for studies regarding different surplus appropriation schemes and their impact on an insurer's risk situation).
} 
where $r^{G}$ is the guaranteed interest rate, $\alpha$ is the annual surplus participation rate and $\gamma$ is the buffer ratio, which must be exceeded in order to allow surplus participation. The policy interest rate must not only be ensured for the traditional participating life insurance contracts, but also for the part of funds of the dynamic hybrid products that is allocated to the insurer's policy reserves at time $t$. In the case of the participating life insurance contracts, the policy reserves in each period are thus increased by

$$
P R_{(t+1)^{-}}^{P L I}=P R_{t^{+}}^{P L I} \cdot\left(1+r_{t}^{P}\right)
$$

A 3-fund dynamic hybrid product invests not only in policy reserves, but also in an equity fund and a guarantee fund, whereby the latter is equivalent to an equity fund with a hedge that ensures a maximum loss of $\lambda$ per cent within one period. In contrast to the participating life insurance policies, where the policy interest rate is guaranteed, we assume that the dynamic hybrid policyholders are guaranteed a fraction $x$ of their single up-front premium,

$$
G_{t}^{D H P}=G^{D H P}=x \cdot P^{D H P} \forall t \in\{0, \Delta t, \ldots, T\}
$$

where $G^{D H P}$ denotes the account value needed at time $t$ to ensure that the guarantee can be met and which may vary depending on the concrete product design. Hence, for $x=1$, the customer obtains a money-back guarantee. In case the guarantee at the end of each period $G_{t+\Delta t}^{D H P}$ can be fulfilled by the guarantee fund only, the dynamic hybrid products' funds are distributed between the guarantee fund and equity fund. The distribution of the account value $A V_{t^{+}}^{D H P}$ to the policy reserves $P R_{t^{+}}^{D H P}$, the guarantee fund $G F_{t^{+}}^{L}$ and equity fund $E F_{t^{+}}^{L}$ is based on Kochanski and Karnarski ${ }^{6}$ and given by ${ }^{11}$

$$
\begin{aligned}
P R_{t^{+}}^{D H P} & =\left\{\begin{array}{cc}
\frac{G_{t+\Delta t}^{D H P}-(1-\lambda) \cdot A V_{t^{+}}^{D H P}}{\left(1+r^{G}\right)^{\Delta t}-1+\lambda} & \text { if } \frac{G_{t+\Delta t}^{D H P}}{(1-\lambda) \cdot A V_{t^{+}}^{D H P}}>1 \\
0 & \text { otherwise }
\end{array}\right. \\
G F_{t^{+}}^{L} & =\left\{\begin{array}{cc}
A V_{t^{+}}^{D H P}-P R_{t^{+}}^{D H P} & \text { if } \frac{G_{t+\Delta t}^{D H P}}{(1-\lambda) \cdot A V_{t^{+}}^{D H P}}>1 \\
\frac{G_{t+\Delta t}^{D H P}}{1-\lambda} & \text { otherwise }
\end{array}\right. \\
E F_{t^{+}}^{L} & =A V_{t^{+}}^{D H P}-P R_{t^{+}}^{D H P}-G F_{t^{+}}^{L} .
\end{aligned}
$$

${ }^{11}$ This mechanism invests the maximum proportion of the account value in the equity fund (and guarantee fund) along with ensuring that the guarantees can still be met. While this is a common system in the market, there are also different approaches aiming to balance the trade-off between the number of shifts, that is, transaction costs, and upside potential (high proportion in equity funds), which thus imply varied risk profiles. 
In what follows, we consider a family of identical 3-fund dynamic hybrid products where funds are reallocated every period.

In sum, liabilities at the end of period $t$ are thus given by

$$
\begin{gathered}
P R_{(t+\Delta t)^{-}}^{P L I}=P R_{t^{+}}^{P L I} \cdot\left(1+r_{t}^{P}\right)^{\Delta t}, \\
P R_{(t+\Delta t)^{-}}^{D H P}=P R_{t^{+}}^{D H P} \cdot\left(1+r_{t}^{P}\right)^{\Delta t}, \\
G F_{(t+\Delta t)^{-}}^{L}=G F_{(t+\Delta t)^{-}}^{A}, \\
E F_{(t+\Delta t)^{-}}^{L}=E F_{(t+\Delta t)^{-}}^{A} .
\end{gathered}
$$

The buffer at the end of a the period $t$ is calculated by

$$
B_{(t+\Delta t)^{-}}=A_{(t+\Delta t)^{-}}-P R_{(t+\Delta t)^{-}}^{P L I}-P R_{(t+\Delta t)^{-}}^{D H P}-G F_{(t+\Delta t)^{-}}^{L}-E F_{(t+\Delta t)^{-}}^{L} .
$$

The company is insolvent if the assets are not sufficient to cover the liabilities, that is, if

$$
B_{(t+\Delta t)^{-}}<0 .
$$

In this case, the remaining funds $R F$ are assumed to be paid out to the policyholders as follows by taking into account the investment in the policy reserves over the contract term (as "surplus" is generated by these means and since dynamic hybrid policyholders still receive their investment in the guarantee fund and the equity fund), that is,

and

$$
R F_{(t+\Delta t)^{-}}^{P L I}=\frac{(1-c) \cdot\left(A_{(t+\Delta t)^{-}}^{\text {longterm }}+A_{(t+\Delta t)^{-}}^{\text {shortterm }}\right) \cdot \sum_{k=0}^{\frac{t}{\Delta t}} P R_{((k+1) \cdot \Delta t)^{-}}^{P L I}}{\left(\sum_{k=0}^{\frac{t}{\Delta t}} P R_{((k+1) \cdot \Delta t)^{-}}^{P L I}+P R_{((k+1) \cdot \Delta t)^{-}}^{D H P}\right)}
$$

$$
R F_{(t+1)^{-}}^{D H P}=\frac{(1-c) \cdot\left(A_{(t+\Delta t)^{-}}^{\text {longterm }}+A_{\left(t+\Delta t^{-}\right)}^{\text {shorterm }}\right) \cdot \sum_{k=0}^{\frac{t}{\Delta t}} P R_{((k+1) \cdot \Delta t)^{-}}^{D H P}}{\left(\sum_{k=0}^{\frac{t}{\Delta t}} P R_{((k+1) \cdot \Delta t)^{-}}^{P L I}+P R_{((k+1) \cdot \Delta t)^{-}}^{D H P}\right)}+G F_{(t+1)^{-}}^{A}+E F_{(t+1)^{-}}^{A},
$$

respectively, if the policy reserves are positive, and where $c$ represents the costs of insolvency. ${ }^{12}$

At maturity $T$, the remaining buffer is distributed among policyholders and equityholders, whereby the equityholders first receive a buffer payback of

$$
B P_{T^{-}}=\max \left(\min \left(B_{T^{-}}, B_{0^{+}} \cdot(1+b)\right), 0\right),
$$

\footnotetext{
${ }^{12}$ See also Grosen and J $\varnothing$ rgensen (2002) for an analysis of early default using barrier options.
} 
which includes a buffer interest rate $b$ paid on their initial investment. The policyholders receive the remainder as an (optional) terminal bonus $T B_{T^{-}}=\max \left(0, B_{T^{-}}-B P_{T^{-}}\right)$, which, analogously to the remaining funds in case of default, is assumed to be distributed between $P L I$ and DHP contracts as follows:

$$
\begin{gathered}
T B_{T^{-}}^{P L I}=\frac{T B_{T^{-}} \cdot \sum_{k=1}^{\frac{T}{\Delta t}} P R_{(k \cdot \Delta t)^{-}}^{P L I}}{\left(\sum_{k=1}^{\frac{T}{\Delta t}} P R_{(k \cdot \Delta t)^{-}}^{P L I}+P R_{(k \cdot \Delta t)^{-}}^{D H P}\right)}, \\
T B_{T^{-}}^{D H P}=\frac{T B_{T^{-}} \cdot \sum_{k=1}^{\frac{T}{\Delta t}} P R_{(k \cdot \Delta t)^{-}}^{D H P}}{\left(\sum_{k=1}^{\frac{T}{\Delta t}} P R_{(k \cdot \Delta t)^{-}}^{P L I}+P R_{(k \cdot \Delta t)^{-}}^{D H P}\right)},
\end{gathered}
$$

if the policy reserves are positive, and zero otherwise. Hence, the total payouts to the participating life insurance and dynamic hybrid policyholders are given by

$$
V_{T}^{P L I}=\left(P R_{T^{-}}^{P L I}+T B_{T^{-}}^{P L I}\right) \cdot 1\left\{T_{s}>T\right\}+R F_{t^{-}}^{P L I} \cdot 1\left\{T_{s}=t\right\}
$$

and

$$
V_{T}^{D H P}=\left(A V_{T^{-}}^{D H P}+T B_{T^{-}}^{D H P}\right) \cdot 1\left\{T_{s}>T\right\}+R F_{t^{-}}^{D H P} \cdot 1\left\{T_{s}=t\right\},
$$

respectively, where the account value if given by $A V_{T^{-}}^{D H P}=P R_{T^{-}}^{D H P}+G F_{T^{-}}^{L}+E F_{T^{-}}^{L}$ and $T_{S}$ denotes the time of default with $T_{s}=\inf \left\{t: A_{t^{-}}^{\text {longterm }}+A_{t^{-}}^{\text {shortterm }}<P R_{t^{-}}\right\}, t=1, \ldots, T$.

\section{Fair valuation and risk measurement}

To ensure a fair situation for the equityholders, the buffer interest rate $b$ is calibrated such that the value of the payout to equityholders is equal to their initial contribution, that is

$$
B_{0^{+}}=E^{Q}\left(B P_{T^{-}} \cdot e^{-T \cdot r_{f}}\right),
$$

where $E^{Q}$ denotes the expected value under the risk-neutral pricing measure $Q$ and $r_{f}$ is the constant risk-free interest rate. Under the risk-neutral measure $Q$, the drift of the investment processes changes to the risk-free rate. ${ }^{9}$

For the fairly calibrated $b$, the present values from the participating life insurance and dynamic hybrid policyholders' perspective are given by

$$
\begin{aligned}
P V_{0}^{P L I}= & E^{Q}\left(\left(P R_{T^{-}}^{P L I}+T B_{T^{-}}^{P L I}\right) \cdot e^{-T \cdot r_{f}} \cdot 1\left\{T_{s}>T\right\}\right) \\
& +E^{Q}\left(R F_{t^{-}}^{P L I} \cdot e^{-t \cdot r_{f}} \cdot 1\left\{T_{s}=t\right\}\right)
\end{aligned}
$$


and

$$
\begin{aligned}
P V_{0}^{D H P}= & E^{Q}\left(\left(A V_{T^{-}}^{D H P}+T B_{T^{-}}^{D H P}\right) \cdot e^{-T \cdot r_{f}} \cdot 1\left\{T_{s}>T\right\}\right) \\
& +E^{Q}\left(R F_{t^{-}}^{D H P} \cdot e^{-t \cdot r_{f}} \cdot 1\left\{T_{s}=t\right\}\right),
\end{aligned}
$$

respectively, which in the case of a fair situation for policyholders should be equal to their initially paid single premiums. We further calculate the shortfall probability under the real-world measure $P$ as

$$
S P=P\left(T_{S} \leqslant T\right)
$$

where

$$
T_{s}=\inf \left\{t: A_{t^{-}}^{\text {longterm }}+A_{t^{-}}^{\text {shortterm }}<P R_{t^{-}}\right\}, t=1, \ldots, T .
$$

\section{Numerical analysis}

\section{Description of input parameters}

The following section presents numerical results based on the model laid out in the previous section. The input parameters are summarised in Table 2 and serve to illustrate central effects. They were further subject to sensitivity analyses. In particular, we assume one period to be one month, that is, the time horizon of $T$ years is

Table 2 Input parameters for the numerical analyses

\begin{tabular}{lll}
\hline Single premiums of participating life insurance contracts & $P^{P L I}$ & 100 \\
Single premiums of dynamic hybrid products & $P^{D H P}$ & 100 \\
Contract duration & $T$ & 10 \\
Guarantee of dynamic hybrid products & $x$ & 1 \\
Initial buffer & $B_{0^{+}}$ & 6 \\
Guaranteed interest rate (p.a.) & $r^{G}$ & 0.0175 \\
Surplus distribution ratio & $\alpha$ & 0.3 \\
Target buffer ratio & $\gamma$ & 0.1 \\
Costs of insolvency & $c$ & 0 \\
Drift of long-term investments & $\mu_{1}$ & 0.045 \\
Volatility of long-term investments & $\sigma_{1}$ & 0.04 \\
Drift of short-term investments & $\mu_{2}$ & 0.035 \\
Volatility of short-term investments & $\sigma_{2}$ & 0.03 \\
Drift of equity fund & $\mu_{3}$ & 0.08 \\
Volatility of equity fund & $\sigma_{3}$ & 0.2 \\
Linear correlation of long-term and short-term investments & $\rho_{1,2}$ & 0.2 \\
Linear correlation of long-term investments and equity fund & $\rho_{1,3}$ \\
Linear correlation of short-term investments and equity fund & $\rho_{2,3}$ \\
Maximal loss of the guarantee fund per period & $\lambda$ & 0.2 \\
Risk-free interest rate & $r_{f}$ & 0.2 \\
Length of a period & $\Delta t$ & 0.20 \\
\hline
\end{tabular}


subdivided with $\Delta t=1 / 12$. The results are generated based on Monte Carlo simulation using 50,000 simulation runs and Latin hypercube sampling to reduce variance. In the following, we particularly study the fair valuation and risk measurement for different input parameters and varying portfolio compositions (in terms of the single up-front premium) in order to identify possible portfolio substitution and risk transfer effects.

\section{The impact of the guaranteed interest rate on fair values and shortfall risk}

The impact of the guaranteed interest rate $r^{G}$ is exhibited in Figure 1 for different portfolios of participating life insurance contracts and dynamic hybrids (only participating life insurance contracts in the first row; equally weighted in terms of the single up-front premium in the second and third row) and different guarantees for the dynamic hybrid (money-back guarantee in second row; guarantee equals 50 per cent of the single premium in the third row). In the right column of Figure 1, the fairly calibrated buffer interest rates are shown (from the equityholders' perspective), and the left column exhibits the corresponding present values of the participating life insurance and dynamic hybrid contracts (left $y$-axis) along with the corresponding shortfall probability of the insurer (right $y$-axis).

The right graphs in Figure 1 show that the fair buffer interest rate $b$ (to be paid to the equityholders) increases (along with an increasing shortfall risk) if the guaranteed interest rate is raised. However, even though all contracts in Figure 1 are fair from the equityholders' perspective, they are not necessarily fair from the policyholders' viewpoint as shown in the left graphs. While the participating life insurance contracts are approximately fair if dynamic hybrid contracts are not sold by the insurer (first row in Figure 1 where the premium by the dynamic hybrid policyholders is $P^{D H P}=0$ ), they are no longer fair in the case of a mixed portfolio (second and third row), that is, as soon as dynamic hybrid contracts are offered in addition to the participating life insurances.

In particular, in the case of a fair situation for both policyholders and equityholders, the present value of each contract type should be equal to the corresponding initial single up-front premium, which in the second row is 100 in the case of both products, for instance. In this setting, the two types of contracts would be fair from the policyholders' perspective (i.e. present value $=100$ for both contracts) for a guaranteed rate of approximately 2.4 per cent, that is, where both curves intersect. Therefore, to ensure fair contracts for shareholders and both groups of policyholders, a corresponding optimisation problem would comprise three objective functions and requires a sufficient number of variable input parameters to solve this problem.

Figure 1 thus demonstrates the strong impact of including dynamic hybrid products in the insurance portfolio on the present value of participating life insurance contracts and on shortfall risk for the considered rebalancing mechanism, whereby the effect also depends on the guarantee $G^{D H P}$ promised to the dynamic hybrid policyholders. In particular, one can observe in the middle left graph (where a money-back-guarantee is embedded in the dynamic hybrid contracts) that for an increasing guaranteed interest rate, the value of the dynamic hybrid product increases, while the present value of the participating life insurance policies decreases. However, the present value of the $P L I$ s lies above their initial premium of 100 , which is most pronounced for low 


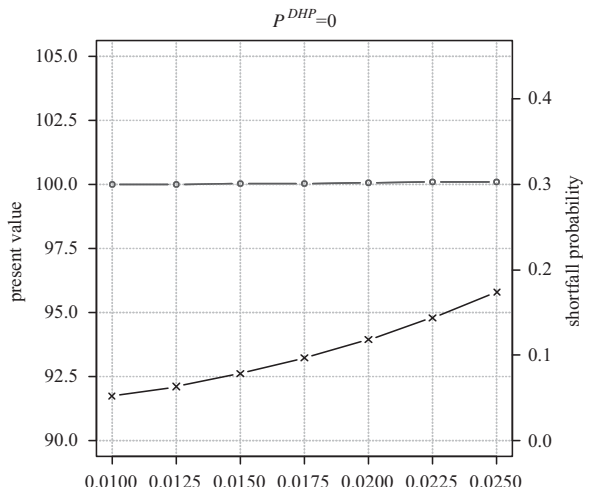

guaranteed interest rate $r^{G}$

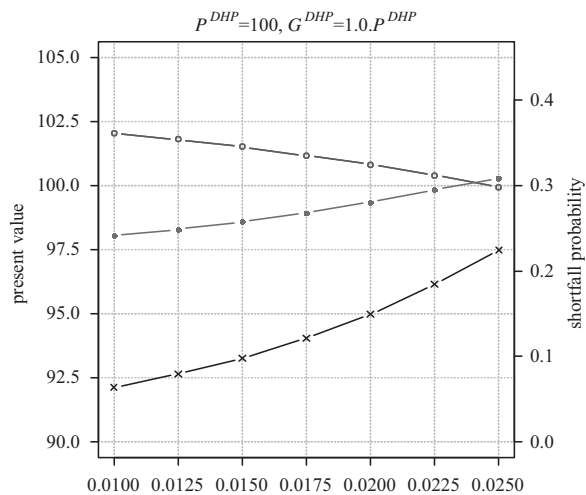

guaranteed interest rate $r^{G}$

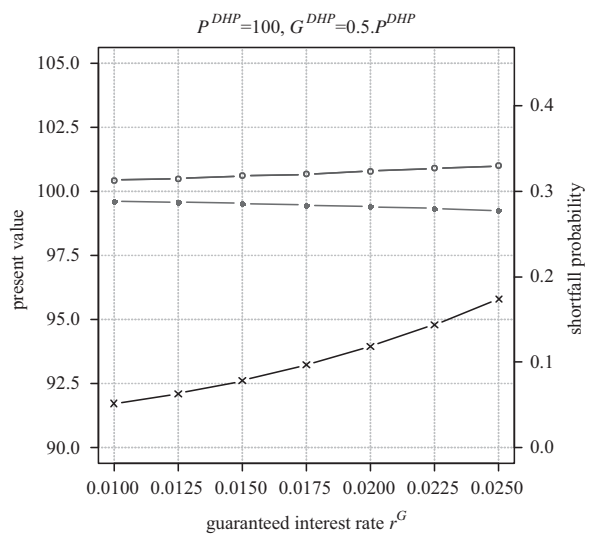

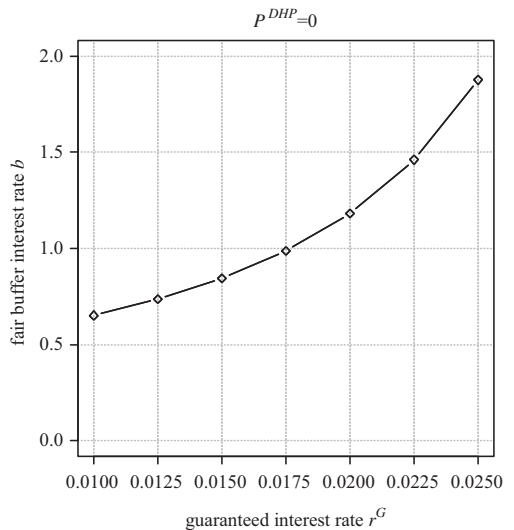
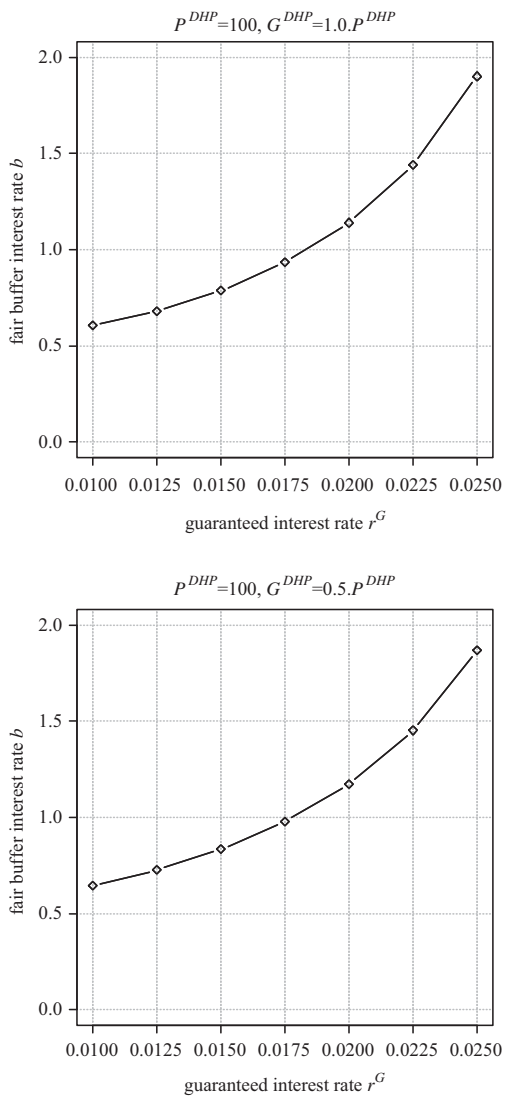

$\multimap$ participating life insurance

dynamic hybrid product $\rightarrow$ shortfall probability (right axis)

Figure 1. Present values of the participating life insurance and dynamic hybrid contracts with corresponding insurer shortfall risk (left column) for different portfolio compositions and dynamic hybrid guarantees when varying the guaranteed interest rate and given fair buffer interest rates (right column, equityholder perspective). 
guaranteed interest rates, while $D H P$ s exhibit a present value well below their initial payment. At the same time, the shortfall probability is higher in the second row (especially for higher guaranteed interest rates) as compared with the case without DHPs (first row).

Hence, the decrease in the present value of PLIs (from a higher level than 100) is caused by the inclusion of dynamic hybrid products. This can be explained when looking at Figure 2, which shows the average monthly partition of the account value $(A V)$ of the dynamic hybrid product over the contract term, that is, the amount of financial resources invested in the three funds (given fair contracts from the equityholders' perspective). The left and right column shows the partitioning for a guaranteed interest rate of $r^{G}=1.0$ and 2.5 per cent, respectively, while from top to the bottom, different guarantees for the dynamic hybrids $G^{D H P}$ are displayed.

As can be seen in the first row of Figure 2, where $G^{D H P}=P^{D H P}$, a higher guaranteed interest rate as shown in the right graph implies that after the first periods, fewer funds need to be allocated to the policy reserves to ensure the guarantee (see also the formula for the dynamic reallocation, which depends on the guaranteed rate). At the same time, a larger part can be allocated to the guarantee fund and the equity fund, which in turn increases the upside potential regarding the average expected payoff for the dynamic hybrid policyholders. However, the shortfall probability of the company as a whole increases due to the higher guarantee also promised to the participating life insurance policyholders. This is also influenced by the fact that the allocation of funds of dynamic hybrids to the policy reserves typically happens in times of low market returns, which makes it difficult for the insurer to generate the necessary guaranteed interest rates by investing in the capital market. Hence, in these times, more money is shifted to the policy reserves and needs to earn at least the guaranteed rate, which is particularly difficult with short-term investments. In addition, as soon as the guarantee is credited to the policy reserves, it becomes part of the guarantee, which also increases the shortfall risk.

As Figure A.1 in the Appendix shows, shortfall mainly occurs in the first contract periods, where not only participating life insurance, but also dynamic hybrid policyholders are still heavily invested in the policy reserves (see Figure 2, first row), which means that, in case of default, the remaining funds of the company are distributed almost evenly between participating life insurance and dynamic hybrid policyholders, whereby the latter group additionally obtains the guarantee fund and equity fund (which are not subject to default in the present setting). Hence, on average and in terms of the present value, dynamic hybrid policyholders profit from the trade-off of a higher return in the sense of an increasing present value (which, however, is still not fair and still below their initial premium payment) and higher shortfall risk in the case of a higher guaranteed interest rate, while the present value of participating life insurance policyholders is decreasing in the trade-off (which would not be the case without dynamic hybrids in the portfolio, see first row in Figure 1), but exhibits an overall higher value as compared with the case without dynamic hybrids. Thus, the situation for participating life insurance policyholders improves in the considered examples, but is deteriorating for increasing guaranteed interest rates.

However, this picture changes when reducing the guaranteed sum insured of the dynamic hybrids from $x=1$ to $x=0.5$ (of the initially paid up-front premium $P^{D H P}$ ) as 

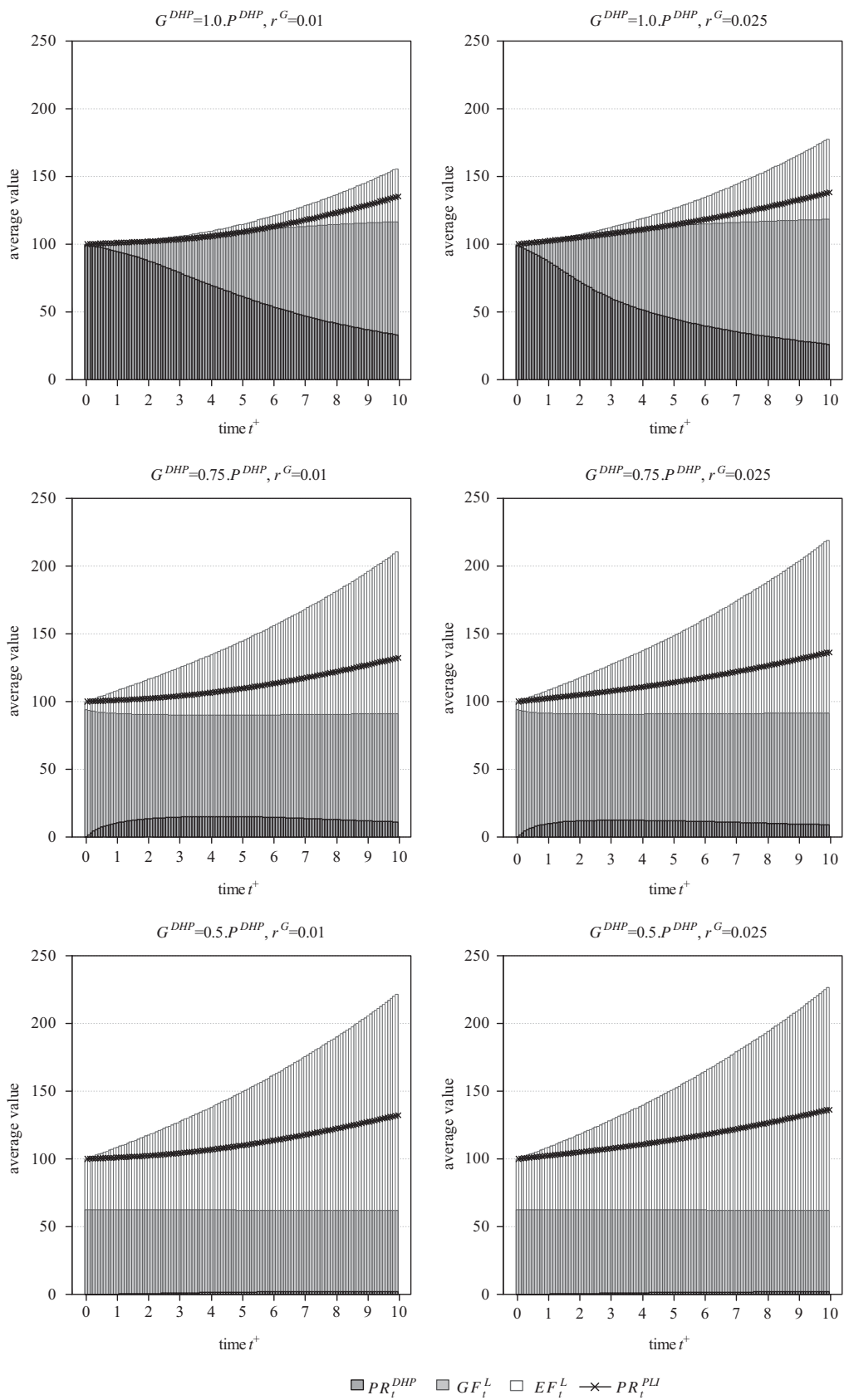

Figure 2. Average partition of the dynamic hybrid product account value into the three funds (equity fund, guarantee fund, policy reserve) over the contract term for different guaranteed interest rates and different dynamic hybrid guarantees given a fair situation from the equityholders' perspective. 
shown in the third row in Figure 1 and the third row in Figure 2. In this case, the present value of the participating policies even slightly increases, while the dynamic hybrid products exhibit a decrease when increasing the guaranteed interest rate. This is true even though only a very small amount of the dynamic hybrid funds is allocated to the policy reserves (since the guaranteed sum insured of the DHPs for the most part can be covered by the guarantee fund $G F$ without need of the policy reserves). While the policy reserves are thus hardly affected by the $D H P$ products and, hence, there is almost no effect on shortfall risk as compared with the case where no dynamic hybrids are sold (first row in Figure 1), the shortfall probability still increases for higher guarantee interest rates. Hence, in case of a default (which is triggered by the participating life insurance contracts), participating life insurance policyholders obtain the vast majority of the remaining funds due to having been invested in the policy reserves, while dynamic hybrid policyholders only receive their current values of the guarantee fund and the equity fund. Hence, for lower dynamic hybrid guarantees, it is the participating life insurance policyholders who profit from the trade-off between risk and return in case of default in terms of an increasing guaranteed interest rate, which is opposed to what we observed in the second row of Figure 2. However, participating life insurance contracts still exhibit a higher present value than their premium payment of 100, while dynamic hybrid policyholders are again below that value for the considered input parameters.

\section{The impact of the surplus participation rate on fair values and shortfall risk}

Looking at the impact of different surplus participation rates $\alpha$ in Figure 3, one can see that the fair buffer interest rates and the shortfall probability are increasing for increasing surplus participation rates, but that this effect is much less pronounced than in the case of the guaranteed interest rate. Furthermore, in contrast to the case of increasing the guaranteed interest rate, the present value of the participating life insurance contract is higher when including dynamic hybrid contracts in the portfolio (second and third row in Figure 3) and increasing for higher surplus participation rates, while the present value of the dynamic hybrid product is decreasing (particularly in the second row in Figure $3, G^{D H P}=1.0 \cdot P^{D H P}$ ). This can be explained by the fact that the mathematical algorithm for the reallocation of funds in the case of the dynamic hybrid products is based on the guaranteed interest rate only, which is constant, while the surplus participation rate (only) contributes to a higher return earned on investments in the policy reserves. Hence, the partition of the dynamic hybrid funds and the total dynamic hybrid account value remains almost unchanged when increasing the surplus participation rate for a given dynamic hybrid guarantee (see Figure 4).

At the same time, the average policy reserves of the participating life insurance policies increase considerably due to the increase in $\alpha$ (see solid black line with stars in Figure 4, compare left and right column), which, associated with the lower shortfall risk as compared with the higher guaranteed interest rate (see Figure A.2 in the Appendix), contributes to an advantage of the participating life insurance contract as opposed to the dynamic hybrid. Thus, while participating life insurance policies are at a disadvantage in the trade-off between higher return and higher risk when increasing 


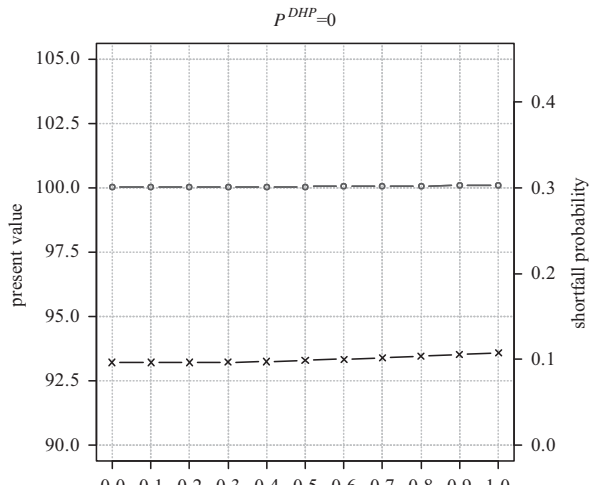

$\begin{array}{lllllllllllll}0.0 & 0.1 & 0.2 & 0.3 & 0.4 & 0.5 & 0.6 & 0.7 & 0.8 & 0.9 & 1.0\end{array}$

surplus participation rate $\alpha$

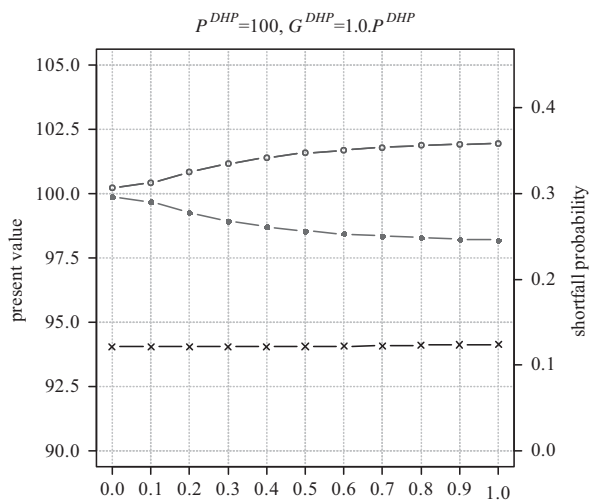

surplus participation rate $\alpha$

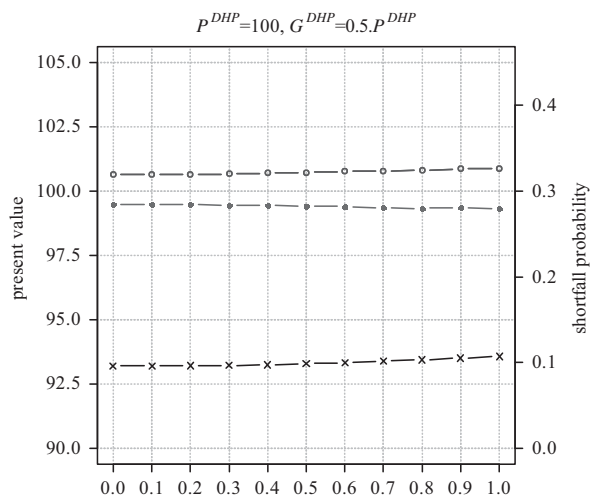

surplus participation rate $\alpha$
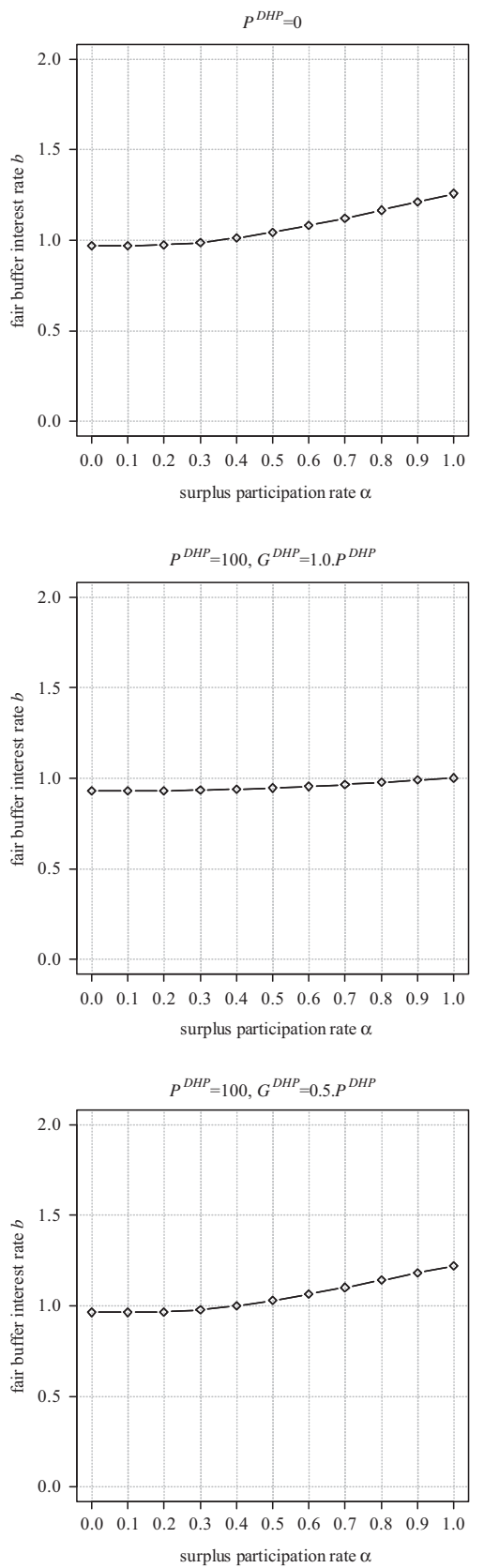

$\leftarrow$ participating life insurance $\leftarrow$ dynamic hybrid product $\rightarrow$ shortfall probability (right axis)

Figure 3. Present values of the participating life insurance and dynamic hybrid contracts with corresponding insurer shortfall risk (left column) for different portfolio compositions and dynamic hybrid guarantees when varying the annual surplus participation rate and given fair buffer interest rates (right column, equityholder perspective). 

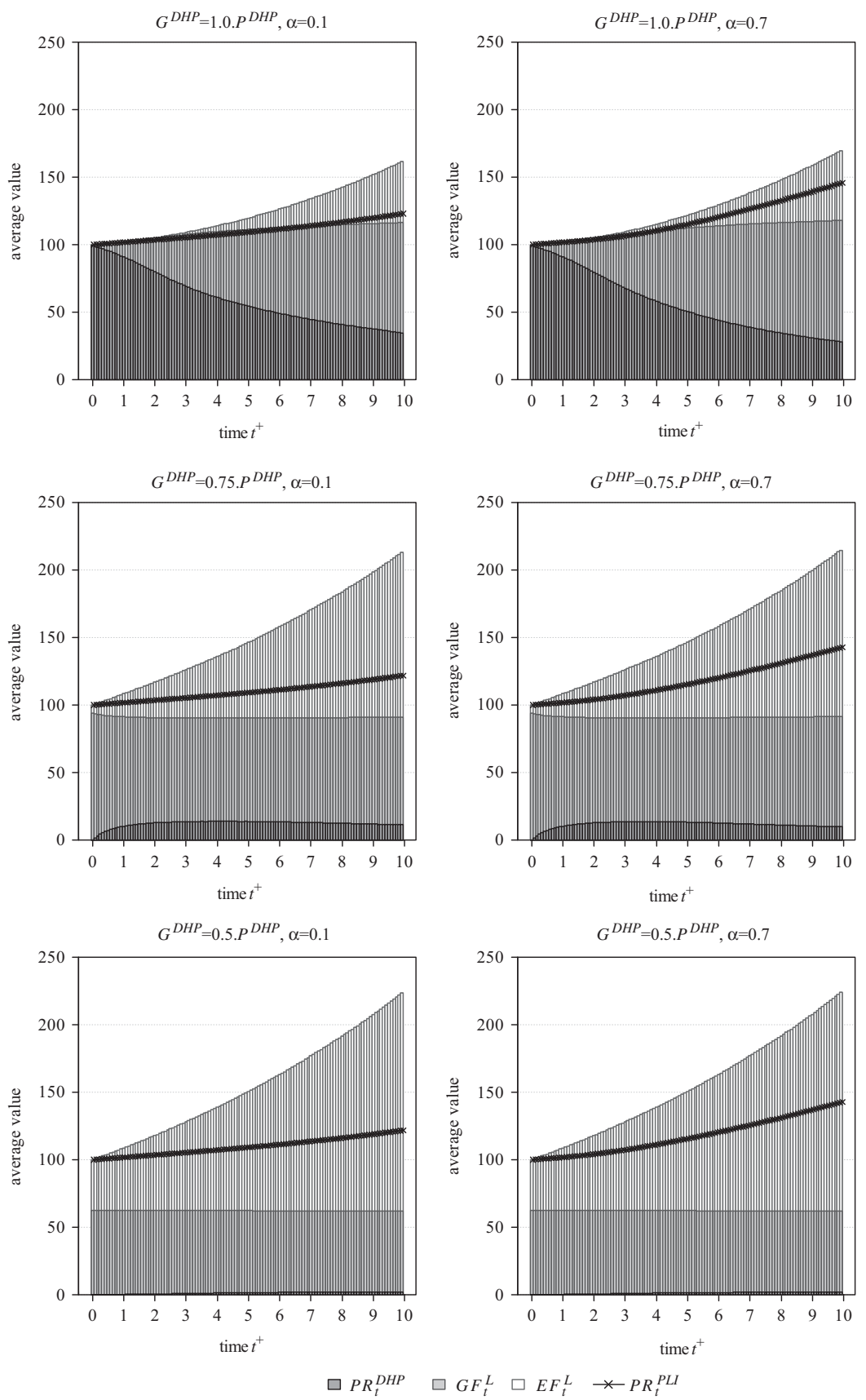

Figure 4. Average partition of the dynamic hybrid product account value into the three funds (equity fund, guarantee fund, policy reserve stock) over the contract term for different annual surplus participation rates $\alpha$ and different dynamic hybrid guarantees given a fair situation from the equityholders' perspective. 


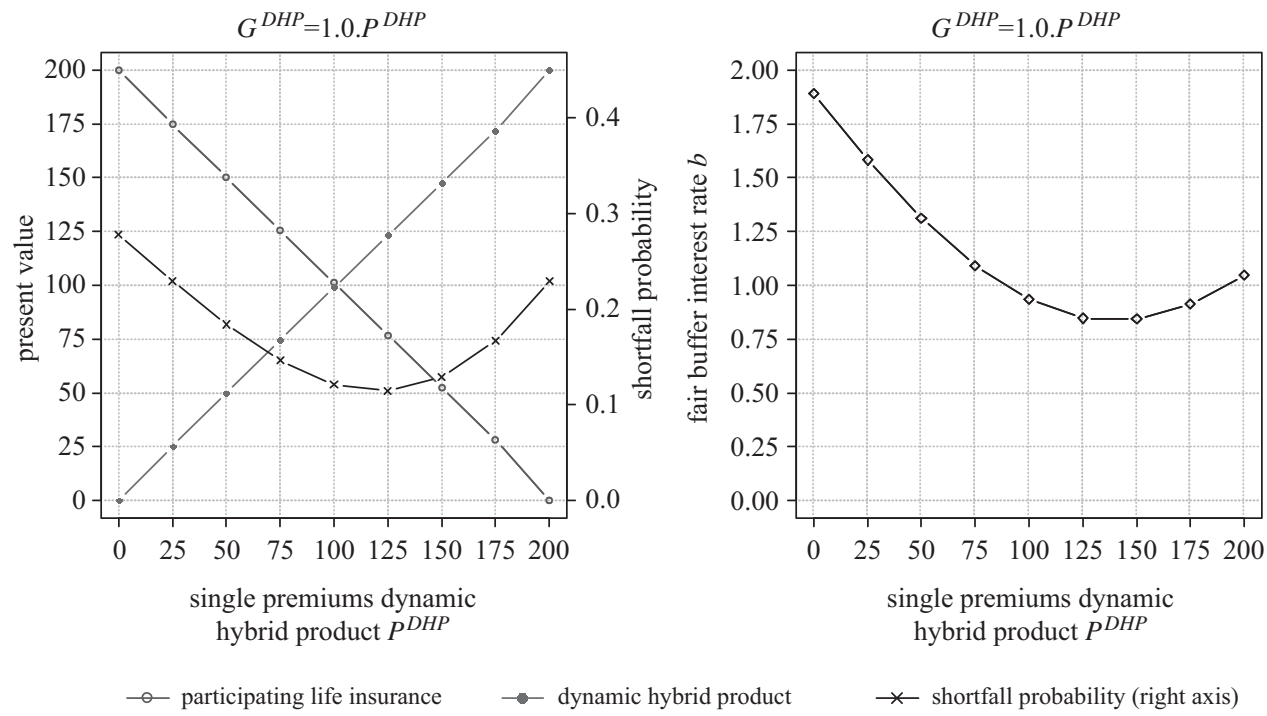

Figure 5. Present values of the participating life insurance and dynamic hybrid contracts with corresponding insurer shortfall risk (left column) when varying the portfolio composition $\left(P^{P L I}=200-P^{D H P}\right)$ and given fair buffer interest rates (right column, equityholder perspective).

the guaranteed interest rate (but still exhibit a positive net present value), they profit in the case of the annual surplus participation rate. When reducing the guarantee level promised to the $D H P$ policyholders to $G^{D H P}=0.5 \cdot P^{D H P}$, Figure 4 shows that, as in Figure 2, almost no funds are distributed to the policy reserves, implying that the situation remains almost unchanged and only slightly improved for the participating life insurance policyholders (see third row in Figure 3).

\section{The impact of the portfolio composition on fair values and shortfall risk}

We next focus on the impact of different portfolio compositions by varying the premium volume of participating life insurance and dynamic hybrid contract as shown in Figure 5 in order to identify further portfolio substitution and risk transfer effects. We thereby fix the total premium volume to 200 and only vary the single premium of the dynamic hybrid contracts $P^{D H P}$, such that the premium of the participating life insurances is given by $P^{P L I}=200-P^{D H P}$.

Figure 5 shows that both contract types are approximately fair, as the present value of the payoff approximately equals the respective premium. ${ }^{13}$ Despite this fact, the shortfall probability varies substantially for different portfolio compositions. Hence, increasing the portion of the dynamic hybrid contracts in the portfolio first implies

${ }^{13}$ Note that in the case of fair contracts, the lines of the present values of both products should be exactly linear in the premium volume. 
a decrease in the shortfall risk, until the portion of dynamic hybrids is $P^{D H P}=125$, which constitutes a minimum. Increasing the portion of $D H P$ s above this level leads to an increase in shortfall risk.

Hence, there is an optimum regarding the shortfall probability in the given setting, which is due to substitution effects. In particular, the fact that the funds of the dynamic hybrids invested in the policy reserves (which depend on the size of the guarantee promised to the dynamic hybrid policyholders, see e.g. Figure 2) are always at least compounded with the same policy interest rate credited to the participating life insurance policyholders' account implies that dynamic hybrid products profit from the long-term investments that are possible due to the long-term commitment of participating life insurances, even though they are only invested short term in the policy reserve. In addition, following the mathematical algorithm, funds are typically shifted to the policy reserves in times of an adverse capital market environment in order to ensure the guarantee promised to the dynamic hybrid contracts. Hence, as the policy interest rate paid to the policy reserves is the same for both contract types, at least the guaranteed rate must be covered by the insurer, which may be especially difficult to achieve in times of low market interest rates, where the guaranteed rate may even be higher than the risk-free rate. ${ }^{14}$ This represents an option granted to the policyholders of the DHPs and the corresponding risk should be accounted for by an insurer, whereby the value of the option also depends on the amount shifted to the policy reserves (and thus the guarantee promised to the dynamic hybrid policyholders in the first place). In addition, in case funds in the policy reserves from dynamic hybrids are not invested short term but long term, hidden reserves may have to be realised if funds are shifted from the policy reserves to the guarantee fund or equity fund. ${ }^{5}$ Furthermore, liquidity risk may arise if the CPPI-based strategy requires a frequent rebalancing, especially in times of market turbulences, which may imply that assets are not as liquid as assumed. ${ }^{15}$ The different guarantees and options as well as associated risks can be reduced by the insurer by adjusting the dynamic reallocation procedure, introducing, for example, limits in regard to the amount shifted between guarantee fund to policy reserves and vice versa or dependent on the stock market environment. $^{5}$

\section{Summary}

This paper assesses the fair valuation and risk assessment associated with an insurer's portfolio that consists of dynamic hybrid policies and participating life insurance contracts. The paper thus contributes to the literature by taking the insurer's perspective in that the portfolio interaction effects by the two products are comprehensively studied. Towards this end, we present a model of a life insurer who offers both types of contracts. The considered 3-fund dynamic hybrid account value is thereby periodically reallocated between the conventional premium reserve stock (corresponding to the policy reserves), a guarantee fund (which loses at most a certain percentage of its value

\footnotetext{
${ }^{14}$ See Menzel (2008) and Siebert (2008).

${ }^{15}$ See, e.g. Rubinstein and Leland (1981).
} 
168

in each period), and a risky equity fund, following a mathematical algorithm that is based on the concept of CPPI.

Our results emphasise that there are strong interaction effects between the two product types, especially as funds allocated to the policy reserves earn the policy interest rate actually determined for the participating life insurance policyholders and, hence, at least a guaranteed interest rate. Even though contracts are calibrated to be fair from the equityholders' perspective, the contracts are not necessary fair for the two life insurance products, whose present values strongly depend on the portfolio composition and the choice of input parameters. In particular, one main finding is that increasing the guaranteed interest rate on average (in terms of the present value) implies an increase in the present value for the dynamic hybrid policyholders, as they profit from the trade-off between a higher return and a higher shortfall risk. However, in the considered examples, their present value still generally stays below their initial premium payment. Participating life insurance policyholders, in contrast, lose in the described trade-off as for increasing guaranteed rates, the present value decreases, which is not the case without dynamic hybrids in the portfolio, where the present value remains approximately constant in the case of a fairly calibrated equityholder interest rate. However, they can also gain from including dynamic hybrid contracts in the portfolio in that the present value of their contracts may stay above their single up-front premium, even if it is decreasing for higher guaranteed interest rates. Our findings also emphasise that the interaction effects depend on the guarantee promised to the dynamic hybrid policyholders, which may be a money-back guarantee or less (or more). In addition, while participating life insurance policies are at a disadvantage in regard to the trade-off between a higher return and a higher risk in the case of increasing the guaranteed interest rate, they profit in the case of increasing the annual surplus participation rate in the sense of an increasing present value, while dynamic hybrid policies show a reduction in the present value of futures payoffs.

Furthermore, as for a lower fraction of participating life insurance contracts in the portfolio, less long-term investment can be made since dynamic hybrid funds are in general not invested long term, the investment return generated by the insurer's assets decreases and the shortfall risk increases, as the guaranteed rate is more difficult to be covered. However, this is only true for low fractions of traditional life insurances in the portfolio, as including dynamic hybrid contracts can also help reducing shortfall risk, in particular since dynamic hybrids feature lower overall guarantees. In the examples considered in the numerical analysis, for instance, the minimum shortfall risk is approximately achieved for an approximately equally weighted portfolio of participating life insurance and dynamic hybrid products (in terms of the single up-front premium). In future research, further analysis is necessary regarding the interdependencies observed in a portfolio with different contract types, for example, with respect to the capital market environment and interest rate dynamics, the impact of transaction costs as well as variations of the rebalancing mechanism, which can be used to adjust the risk-return profile of the dynamic hybrids. In addition, the impact of mortality risk and management rules regarding assets and profit participation on portfolio effects could be studied to identify further interaction effects. 


\section{References}

Bettels, C., Grosner, T. and Leitschkis, M. (2011) 'Vorsorge: Dynamische Hybride: Chancen und Risiken für Lebensversicherer', Versicherungswirtschaft 66(20): 1451-1457.

Björk, T. (2009) Arbitrage Theory in Continuous Time, 3rd edn. New York: Oxford University Press.

Black, F. and Jones, R. (1987) 'Simplifying portfolio insurance', Journal of Portfolio Management 13(3): 48-51.

Bohnert, A. and Gatzert, N. (2012) 'Analyzing surplus appropriation schemes in participating life insurance from the insurer's and the policyholder's perspective', Insurance: Mathematics and Economics 50(1): 64-78.

Grosen, A. and Jørgensen, P.L. (2000) 'Fair valuation of life insurance liabilities: The impact of interest rate guarantees, surrender options and bonus policies', Insurance: Mathematics and Economics 26(1): 37-57.

Grosen, A. and Jørgensen, P.L. (2002) 'Life insurance liabilities at market value: An analysis of insolvency risk, bonus policy, and regulatory intervention rules in a barrier option framework', Journal of Risk and Insurance 69(1): 63-91.

Kochanski, M. and Karnarski, B. (2011) 'Solvency capital requirement for hybrid products', European Actuarial Journal 1(2): 173-198.

Leland, H.E. (1980) 'Who should buy portfolio insurance?', Journal of Finance 35(2): 581-596.

Menzel, P. (2008) 'Optionen in dynamischen Hybridprodukten', Der Aktuar 14(1): 9-12.

Rubinstein, M. and Leland, H.E. (1981) 'Replicating options with positions in stock and cash', Financial Analysts Journal 37(4): 63-72.

Siebert, A. (2008) 'Aktuarielle Fragen zu dynamischen Hybridprodukten', Der Aktuar 14(2): 79-82. 


\section{Appendix}
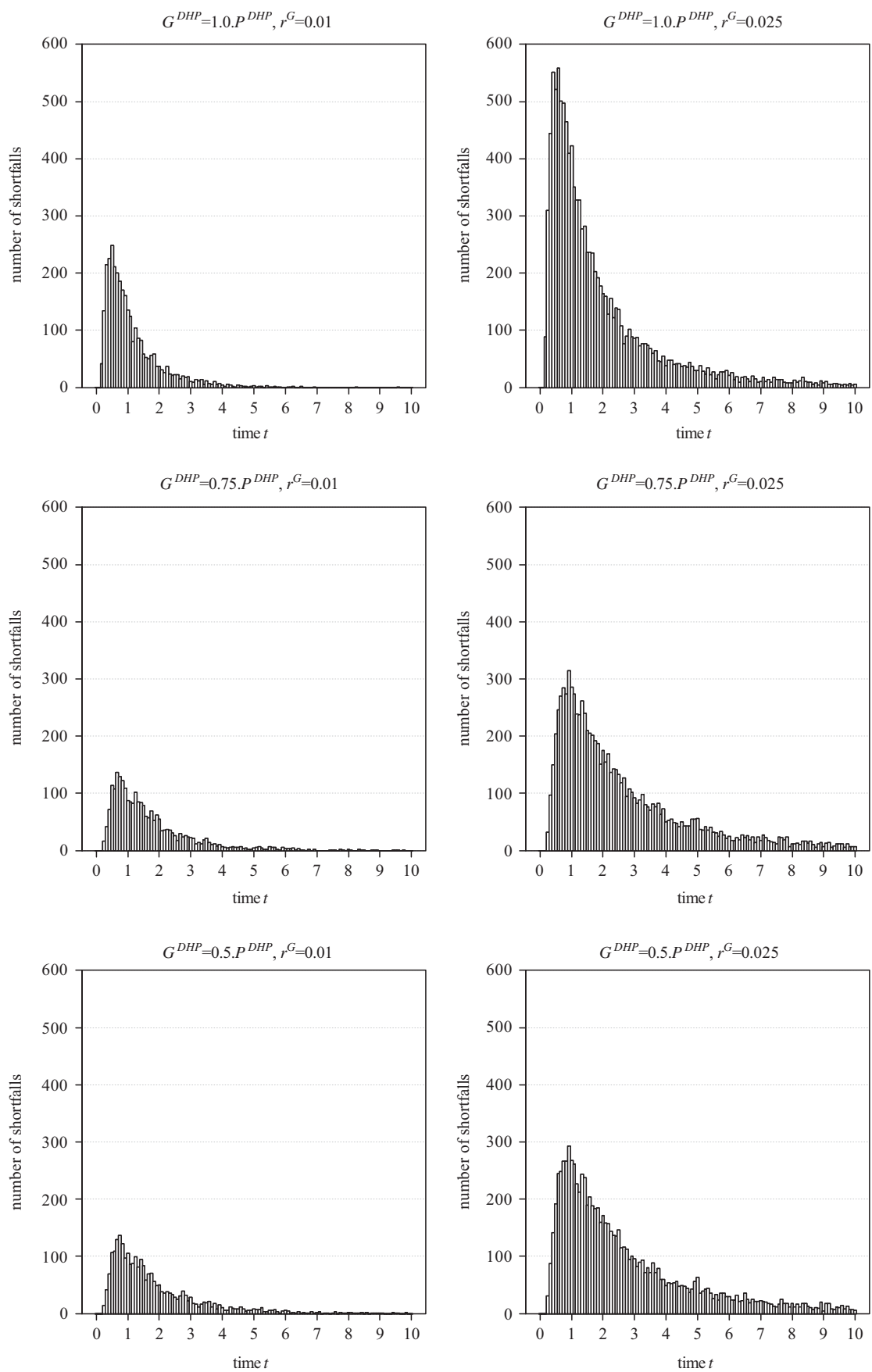

Figure A.1. Number of shortfalls per period corresponding to the situation in Figure 2. 
Alexander Bohnert and Nadine Gatzert

Fair Valuation and Risk Assessment of Dynamic Hybrid Products in Life Insurance
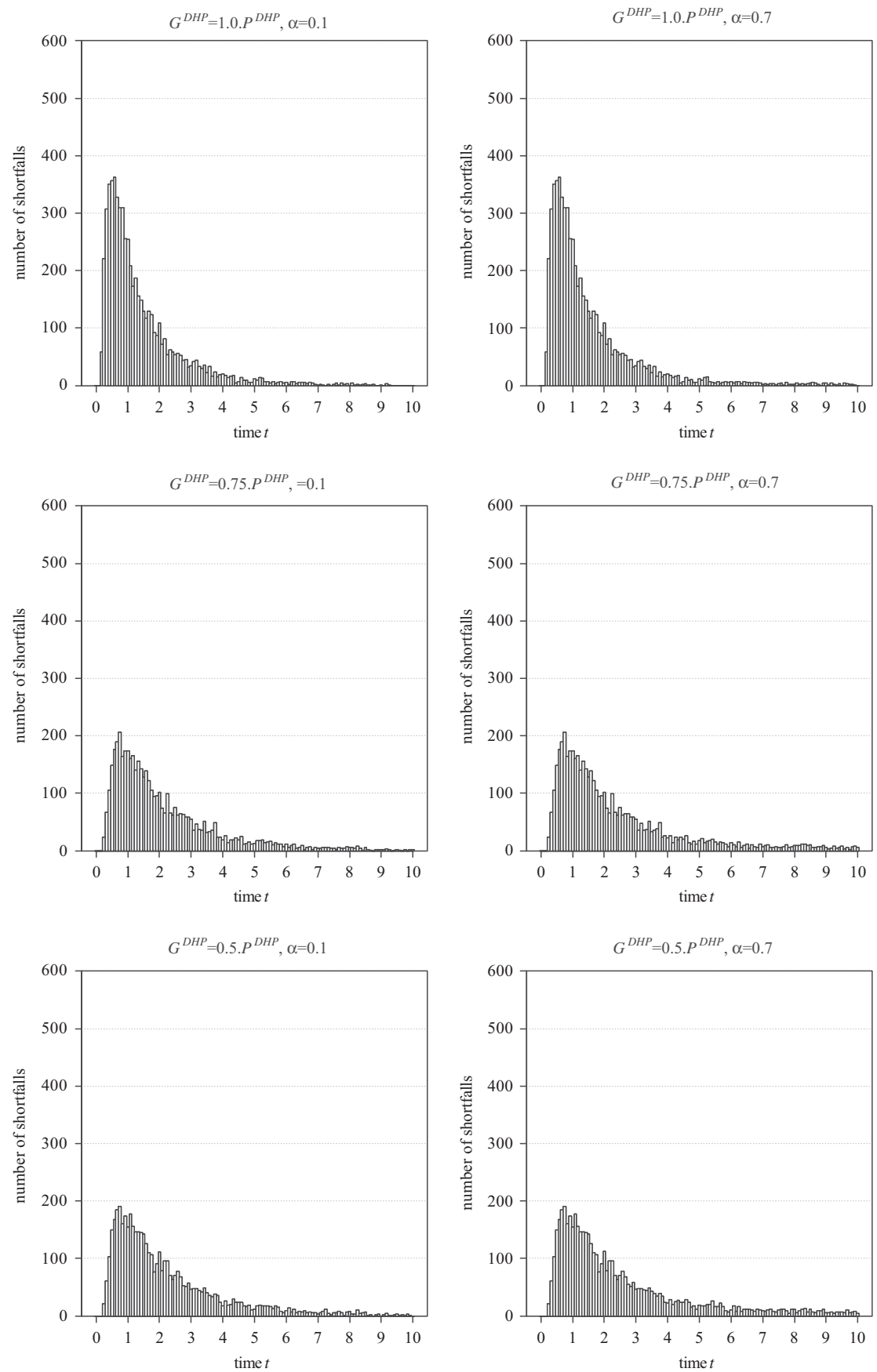

Figure A.2. Number of shortfalls per period corresponding to Figure 4. 


\section{About the Authors}

Alexander Bohnert is a doctoral student and research assistant at the Department of Insurance Economics and Risk Management, Friedrich-Alexander-University of Erlangen-Nürnberg, Germany. Prior to that, he studied mathematics and economics at the University of Ulm, Germany, and at the University of West Florida, Pensacola, U.S.A. His main research interests lie in the field of life insurance including valuation, risk assessment and risk management.

Nadine Gatzert studied mathematics and economics at the University of Ulm, Germany, and at the University of Southern California in Los Angeles, U.S.A., majoring in Mathematical Finance and Actuarial Science. She received her doctoral degree in 2007 and her postdoctoral qualification in 2009 from the University of St. Gallen, Switzerland. Since 2009, she holds the Chair for Insurance Economics and Risk Management at the Friedrich-Alexander-University of Erlangen-Nürnberg, Germany. Her main research interests include enterprise risk management, financial guarantees, alternative risk transfer and regulation in the financial services industry. 